\title{
Algumas imagens sobre docência e formação na década de 60: revisitando a Revista Brasileira de Estudos Pedagógicos*
}

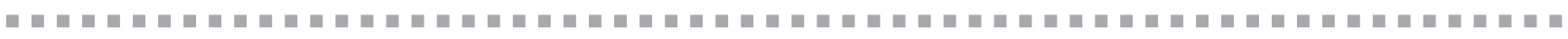
Inês Ferrei ra deSouza Bragança

Palavras-chave: memória; docência; formação de professores.

\section{Resumo}

O presenteartigo busca concepções sobre docência eformação em artigos publicados pela Revista Brasileira de Estudos Pedagógicos (RBEP) na década de 60, com a perspectiva de capturar al guns lampejos do passado, de momentos de perigo, densos de contradições e de possi bi lidades para a educação brasileira. Para tanto, primei ramente, mergul hamos no estudo de artigos que tratam das referidas questões, para, em um segundo momento, anal isarmos as relações da problemática tal como foi posta naquel e contexto e como se apresenta nos desafios atuais.

\section{Apresentação}

apartirdorelatório apresentado ao grupo de pesquisa "Destruição eReinvenção daEscolaPública: Tensões na Formação de Professores", coordenado pela professora Célia Frazão Soares LinharesnaUniversidadeFede ral Fluminense(UFF), em 1998.

1 A listagem dos artigos estuda dosencontra-senas referências bibliográficas.

2 As questões trazidas pelalite ratura educacional, bem como aanálisedesenvolvida, situamsedentro do movimento múltiplo dahistóriaedaprodução do conhecimento; revelam-se, portanto, semprecomo uma, entreoutras possibilidades de análise. Focalizamos a década de60 eespecificamenteosartigos publicados pela RBEP que tratam da formação de professorese efetivamos umaanálise restritaa estematerial, definindo, assim, um necessário corte epistemológico.

3 Para apresentação desteitem Para apresentação desteitem,
especial menteo levantamento deproblemas, referenciais teóricoseal ternativas, bemcomo para composição das "imagens sobrea docência", foramanalisados todos os artigos da RBEP listados nas referências bibliográficas enão somente os que estão diretamente citados no texto.
Buscando concepções sobre docência eformação, visitamos al guns arti gos sobre a formação de professores de Ensino Fundamental na Revista Brasileira de Estudos Pedagógicos (RBEP), publicados na década de $60,{ }^{1}$ com a perspectiva de trazer alguns lampejos do passado, de momentos de perigo, densos decontradições e depossibilidades para a educação brasileira. Walter Benjamin ilustra esse processo com a imagem do Angelus novus, de Paul Klee, que, ao mesmo tempo que ol ha o passado, éarremessado para o presente (Gagnebin, 1993). Assim, encontramos na literatura questões quese colocam, ainda hoje, como desafio para aquel es que produzem a profissão docente.

A década de 60 constituiu, portanto, um período histórico de muitas tensões e possibilidades para a sociedade brasileira e para o sistema educacional. E, nesse contexto, que concepções sobre docência eformação são veiculadas pelo ideário educacional? Que referenciais teóricos fundamentam essas proposições? Quais os principais problemas equai s as al ternativas para a formação de professores propostas pela literatura educacional? Como esses problemas se colocam, hoje, no campo educativo?

Para tanto, primeiramente, mergulhamos no estudo de artigos produzidos na década de 60 que tratam das al usi vas questões, para, em um segundo momento, anal isarmos as relações da problemática tal como foi posta naquele contexto e como se apresenta nos desafios atuais. ${ }^{2}$

\section{Lampejos da literatura estudada ${ }^{3}$}

Lourenço Filho, em 1960, afi rma que a concepção social sobre o professor e seu trabal ho encontra-se mediada pel o momento histórico. Desta forma, "transitamos dos figurinos sociais, de quase exclusiva concepção técnica, para os model os íntimos que cada professor logre criar em si mesmo, em relação à sua profissão e à sua pessoa, dentro da profissão" (p. 42). A análise dos textos procurou, então, compor uma "imagem" sobre o professor e seu trabal ho na literatura estudada. 


\section{Problemas, referenciais teóricos e al ternativas}

A partir da literatura estudada, destacamos três dimensões: um conjunto de problemas que são atribuí dos à formação docente, os referenciais que fundamentam as discussões apresentadas e as alternativas propostas naquele momento histórico.

Ressaltamos, assim, como problemas: a relação teoria e prática, sendo considerados, nesse caso, a real ização de cursos desligados dos probl emas da escola primária, o currículo queaponta o desequilíbrio entrea formação teórica e prática, a mai oria dealunos que não completam o estudo de metodologia com observações de aula, professores de prática de ensino com pouca experiência nas escolas primárias; a questão profissional e o currículo, sendo debatidos os problemas das escolas normais que não desenvolvem o espírito profissional, do conteúdo que oferecem ao al uno como não adequado às variáveis necessi dades dos al unos ou às exigências atuais da profissão, dos currículos enciclopédicos, do número de disciplinas como muito grande e dificultando não só um estudo aprofundado que ofereça condi ções de articul ação interna, mas também com os problemas da profissão; finalmente, o abandono do curso e do magistério, dificuldade dos professores com os problemas infantis, necessidade de maior acompanhamento dos professores novos, grande número de professores leigos.

Os problemas destacados sinalizam uma concepção de educação e deformação docente, e muitos desses problemas se recol ocam em diferentes contextos históricos. Destaca-sea questão da dificul dade de articulação teoria e prática, que tem sido recorrentenaliteratura educacional sobrea formação de professores. Os currículos enciclopédicos, com um excessivo el enco de disciplinas, apontam para uma ênfase na formação geral que não vem permeada por uma relação dialética com a prática educativa, com o contexto social e com as exigências da profissão.

Registra-se o fenômeno da "evasão de professores", quehojese manifesta deforma acentuada no sistema educacional brasileiro. Naquele período histórico, as normal istas abandonavam os cursos pela fal ta de tempo, pel os encargos familiares, e $50 \%$ dos al unos e al unas cursavam sem ter interesse de dedicar-se à profissão.
Havia procura dos cursos normais pela classe média, ${ }^{4}$ e o ofício de professor representava status social; hoje, os baixos salários, a imagem social do trabal ho docente e as condições de trabal ho levam ao abandono da profissão.

Quanto aos referenciais teóricos, observamos uma ênfase nos estudos psicológicos. Questionados quanto às dificuldades da prática docente, os professores destacam os "problemas infantis" como dificuldades de aprendizagem, de comportamento e disciplina em geral. Não há menção a questões da prática pedagógica ou denatureza cultural esocial, já que a Psicol ogia vem como a ciência que pode dar suporte para análise do fenômeno educativo.

Os textos analisados apresentam um caráter de denúncia da situação existente, apontando, contudo, para poucas propostas de intervenção. Como alternativa para a formação de professores, registra-se referência à extinção da nomeação de leigos eorganização de instituições destinadas à formação do magistério, em regimeintensivo, preparando professores para locais carentes. Diante da problemática dos al tos índices de evasão e repetência, a solução apontada é para o preparo profissional do professor.

Não hácomo deixar de estabelecer, deimediato, correlação entre os índices de repetência eevasão ea situação já exposta, relativamente à qualificação do professorado no Brasil.

Não há, porém, a menor dúvida de que, entre as várias razões que determi nam a evasão escolar, temos a de que o próprio professor não consegue atrair e reter o aluno... (Pinheiro, 1966, p. 22). ${ }^{5}$

Háumacertatendência deculpabilização do professor quanto aos problemas do sistema educacional. Nesse sentido, a formação continuada vem como uma resposta linear à problemática da escola, panacéia que pode resolver todos os males.

\section{Imagens da docência}

Ostextos trazem, também, uma imagem sobre o trabal ho docente, que se define especial mente por características atribuídas ao professor.

... o professor há de ter energia e paciência; prazer em comandar e desejo de servir, capacidade de afirmação e, algumas

\footnotetext{
4 "... em relação à inserção de classe, os professores primários têm estado vinculados, historicamente, às classes médias e que esta categoria teve uma movimentação defrações desta mesma classe social: no século passado, eram recrutadas entreas mulheres das camadas pobres, órfãs abrigadaseminstituições de caridade, posteriormentefilhas defamílias das classes médias urbanas, nas décadas de 40, 50 e 60, entre famílias cujos chefes executavam trabal hos não-manuaise possuíam renda familiar alta, e, na década de 70 , entre mais baixas desta mesma classe" (Pessanha, 1994).

5 O texto Treinamento, formação eaperfeiçoamento de professores primários e o Plano Nacional de Educação, deautoria da professoraLúciaMarquesPinheiro, constitui "informeelaborado pelaDivisão deAperfeiçoamento do Magistério do Centro Bra sileirodePesquisasEducacionais paraall ConferênciaNacional e Educação", sobaorientação dare feridaautora(Pinheiro, 1966).
} 
vezes, capacidade de dissi mulação. Há de reunir, enfim, al guns poderes angélicose outros demoníacos... (Lourenço Filho, 1960, p. 49).
Das características citadas nos artigos estudados, destacam-se:

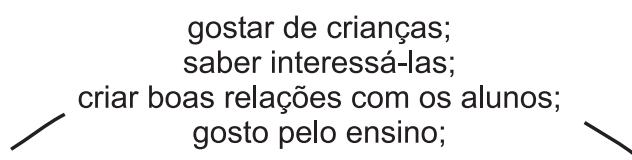

amor ao próximo; capacidade de doação: autodomínio; controle emocional; saúde, simpatia, entusiasmo;

um pouco jornalista; um pouco cientista; um pouco autor de enciclopédias; operador de recursos tecnológicos; preparador e sacerdote profundamente integrado na cultura científica; imaginação;

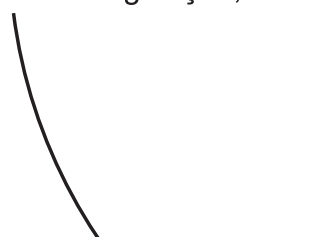

aspecto agradável; personalidade emocionalmente equilibrada; presença que inspire confiança e serenidade.

maturidade psicológica; perseverança; grande interesse pelo Brasil; interesse por assuntos intelectuais, por Arte, pelo trabalho manual, pela cultura geral;

faculdade de renovação perpétua; constante necessidade de aperfeiçoamento; hábito de ler; desejo de renovar-se;



Essas definições do professor sinalizam uma imagem do trabal ho docente como uma "doação pessoal", em que alguns dos el ementos são traços do temperamento, da aparência, do estilo pessoal de relacionamento com as pessoas. O elemento "sacerdotal " da profi ssão docente é explicitamente descrito, havendo fortes referências a el ementos da moral cristã. O professor/professora deve ter características que apontem para o autodomínio, o control e emocional e maturidade intelectual. Observa-se uma tendência general ista que inclui arte, trabalho manual, cultura geral, ciência e os recursos tecnológicos. O professor/professora deve ter o desejo de constante aperfei çoamento, o hábito de ler e muita imagi nação.

Os textos trazem, ainda, referências que definem o trabal ho docentecomo uma tarefa fundamental mentefeminina, em que "a mestra representaria o papel demãe" (Rosas, 1967, p. 126).
A superioridadefemininano ensino, queéincontestável, sobretudonograu primário, advém demaior intuição psicológica da mulher, sua maisfinasensibilidadeou sentidoestético(LourençoFilho, 1960, p. 49).

...queomagistérioécarreiraprópria paraamuIheremvistade"instinto maternal", dapaciênciaedocilidadefemininas(Realizações..., 1962, p. 119).

As características citadas anteriormente seconcretizam naimagem da "mãe" ou da "tia", que deveser doce, amável, sensível epaciente. A professora como "guardiã da moral ", responsável pelaformação dehábitos comojustiça, leal dade, generosidade, tolerância, cola boração, solidariedade, honestidade.

São tarefas da escola primária manter a necessária base de estabilidade social , para que o progresso se faça sem abalos, sem destruição das normas morais... (Real izações..., 1962, p. 108-109). 
A tarefa atribuídaà escola primária encontra-se com a imagem do(a) professor(a) alinhavada pel os textos, propondo tarefas que visam à formação de sujeitos "conformados" com a real idadesocial, preparados para defender a estabilidade e o progresso.

Reafirmamos, contudo, queestaéapenas uma das leituras possíveis: uma imagem da docência quefoi construída a partir de fragmentos e vem, necessariamente, imersa no contexto histórico que a produziu. Ressal tamos, ainda, que esta se coloca como o referencial mais amplo da política macroeducacional, pois, no cotidiano, os educadores/intel ectuais, que constituíam o campo educativo, indicavam combatividade no enfrentamento das questões postas como desafios para a docência e para a formação, desafios estes que se reapresentam hoje e que precisam ser enfrentados.

\section{A formação de professores - leitura a "contrapelo"}

Na leitura dos textos, identificamos al gumas das questões que ainda hoje se colocam como problemas no campo educativo. Neste item, perseguimos o rastro dessas questões, fazendo o movimento passado-presente. Buscamos uma reflexão sobre docência e formação, e nos parece interessante a confluência deal gumas preocupações.

Lourenço Filho (1960) traz a compreensão deuma interdependência entre vida pessoal e profissional, pois, segundo este autor, val orizar a profissão significa val orizar a si mesmo. A literatura nacional einternacional tem apontado para esta questão. Maria da Conceição Moita afi rma quea formação éuma ação vital de construção de si mesmo, éa dinâmica em quesevai construindo a identidade de uma pessoa: "Processo em que cada pessoa, permanecendo el a própria e reconhecendo-se a mesma ao Iongo da sua história, seforma, setransforma em interação". Pesquisas real izadas destacam um forte impacto da vida familiar e social sobrea vida profissional dos professores. O espaço profissional é aberto a outras experiências, sendo fonte de conflito, tensão, mas também de enriquecimento. Identidade pessoal e profissional estabelecem uma variedade de rel ações que produzem autocriação e transformação (Nóvoa, 1992a, p. 114-115 e 131).
Há uma ênfaseno aperfei çoamento dos professores no sentido de desenvol vimento da "consciência profissional". O aperfeiçoamento éconceituado como "uma ação continuada e progressiva", e deve, segundo Lourenço Filho (1960, p. 42), constituir cursose estudos nas próprias escolas. O conteúdo desses cursos deveestimular a ampliação da cultura dos professores. Esta ênfase no "aperfeiçoamento de professores" vem ao encontro das pesqui sas atuais que enfatizam o processo deconstrução continuada da formação docente, quesedesenvolve, prioritariamente, no cotidiano da escola.

O processo de "investi gação ativa" vem, naliteratura estudada, como uminstrumento quevisa transformar a situação concreta existente. "O que temos exatamente de fazer? É isso que, real mente, estamos fazendo? Senão estamos, por que tal acontece?" (Lourenço Filho, 1960, p. 45-46). A proposição da "investigação ativa" nos reporta ao processo de refl exão-na-ação, formulado por Schön (Nóvoa, 1992b), segundo o qual o professor é um intel ectual que atua promovendo a revital ização da prática. O professor permite ser surpreendido pelo que o aluno faz, reformula o problema e efetua uma nova experiência. Este é o processo no qual o professor encoraja a confusão do al uno ea sua própria confusão, no sentido de promover a aprendizagem e a ressignificação constante das práticas pedagógi cas. A atitude de estudo permanenteé característica da ação docente.

Lourenço Filho (1960, p. 52) estabelece ciclos no trabal ho docente, segundo o qual seria preciso, no mínimo, cinco anos para ser bem classificado numa escala de eficiência; essa posição é mantida até o vigési mo ano ea partir daí se começa a declinar. De acordo com a perspectiva dos "ciclos de vida profissional", os professores passam por diferentes fases ou etapas.

\footnotetext{
Todas elas têm características próprias, havendo, porém, a considerar que uma nova fase pressupõea al teração das características da anterior e a assunção de novas características, fruto, muitas vezes, de circunstâncias al eatórias, e que em cada fase essas características se organizam de modo específico, por referência às fases anteriores e às que se seguirão (Gonçal ves apud Nóvoa, 1992a, p. 148).
}

Por meio de uma pesquisa, Gonçalves (apud Nóvoa, 1992a, p. 164) definiu cinco etapas na carreira docente. Os primeiros 
quatro anos são o "início" da profissão e se caracterizam pel o choquecom o real eadescoberta deum mundo novo. Nessemomento, misturam-se a fal ta de preparação, condições difíceis de trabal ho, al inhando-se a uma luta entre a vontade de se afirmar eo desejo de abandonar a profissão.

Entre os cinco e sete anos, podendo prol ongar-seatéos dez, registra-se um momento de "estabilidade", onde o(a) professor(a) al cança confiança na gestão de ensino-apren dizagem ea satisfação pel o trabal ho. Oscilando entre 8 e 15 anos, há um período de "divergência", de desequilíbrio, em que uns procuram investir na profissão e outros demonstram cansaço e saturação. A quarta fasecaracteriza-sepela sereni dade (entre 15 e 20-25 anos), fruto de queda do entusiasmo e um certo distanciamento afetivo. De 31 a 40 anos de serviço há, para al guns, uma "renovação do interesse", de monstrando-seentusiasmado para continuar e aprender coisas novas, e, para outros, uma fase de desencanto, em que só se espera a aposentadoria. Confrontando-se as proposições de Lourenço Filho (1960) eGonçal ves (Nóvoa, 1992a), observamos a confluência de interesses na anál ise da trajetóriadocente.

Encontramos no texto de Pinheiro (1966, p. 26) outra problemática queainda hojesecoloca deforma visível eérecorrente na literatura educacional:

É evidente que a pedagogia encontrada nas escolas primárias não assimilou as contribuições científicas de nosso tempo, o espírito da moderna fil losofia da educação, as técnicas que influem na arte de ensinar o espírito de investigação e de aperfeiçoamento contínuo.

A questão col ocada nos reporta à fragmentação no campo pedagógico e ao atravessamento entreteoriae prática. Se, por um lado, as temáticas desenvolvidas em pesquisas educacionais se distanciam da escola básica, por outro, as produções existentes não passam por um processo de validação social, já quechegamà escola ecaem no vazio, pois o professor étido como mero executor.

Linhares (1991) sinal iza o "abismo entrea intel ectualidade acadêmica e a escola básica":

Esta distância entre os que pensam e fazem a educação escolar esteriliza a pesquisa, tornando-a artificial, pois a impede de penetrar na problemática viva da escola, de conviver e confrontar-se com a real idadepedagógica queseconstitui como prova efetiva da validade das teorias.

A literatura internacional destaca quea "profissi onal ização do saber na área das Ciências da Educação" traz a desval orização dos saberes experienciais e práticos dos professores, aumentando a distância da produção do saber pedagógi co do cotidiano escolar (Nóvoa, 1992b, p. 27).

Popkewitz (1992), no artigo "A profissionalização de professores: algumas notas sobre sua história, ideol ogia e potencial", destaca que o século 19 divulgou a concepção de profissional ização esua referência à posse de conhecimentos teóricos especializados. NosEUA, especialmente no campo educativo, este processo seconcretizou no século 20, quando "a ciência legitimou a organização do trabal ho sobre o currículo ea aprendizagem, numa estratégia para racionalizar o conhecimento dos professores sobre a prática pedagógica". Foi a Psicologia Cognitiva quevei o direcionar "o modo como os professores pensam e refletem sobresua prática" (Nóvoa, 1992b, p. 43 e 45).

Compreendemos a formação continua da de professores no cotidiano da escola como uma alternativa para este processo (Souza, 1997). Por meio de movimentos individuais e col etivos, os professores produzem uma rede deinterdependências esabe res pedagógicos que podem revitalizar as práticas. Nesse movimento, o registro assume um papel fundamental, pois constitui a memória da escola e a afirmação dos saberes dos professores.

Pinheiro faz uma relação entre memória e formação de professores nas seguintes afirmações:

Como esperar que se tornem educadores e não meros repetidores ao que aprenderam em suas escolas primárias quando alunos?

A Pedagogia ativa não éusada e nisto reside, sem dúvida, uma das dificuldades que encontram os professores em aplicá-las na escola primária. Embora tenha notícia ou conheça teoricamente os métodos de ensino mais atual izados, o professor - queos não exercita suficientemente durante a formação - quando se vê diante das classes primárias vol ta às práticas rotineiras de seu tempo dealuno, queestão mais bem integradas em seu comportamento (Pinheiro, 1966, p. 35-36). 
A formação de professores passa pelos arquivos da memória e começa muito antes da opção pelo magistério como profissão, pois desde cedo aprendemos com nossos professores e professoras formas de lidar com a dinâmica da escol a e da sala de aula eformas de concretização do currículo. É preciso ressignificar esses anos escolares, as histórias surpreendentes boas e ruins que vão se acumulando, constituindo imagens sobre o ofício de professor.

\section{Para refletir}

Este trabal ho busca "indícios e sinais" (Ginzburg, 1989) sobre o professor eseu trabalho, indícios quenos instigame se desdobram em outras perspectivas de pesquisa.
A reflexão aponta para o quanto a imagem sobre o ofício docente vem marcada pelo contexto epel os referenciais históricos quea produziram. Apesar das marcas diferenciadas entrea produção da década de 60 eas pesquisas contemporâneas sobre docência eforma ção, épossível, contudo, identificarmosquestões que se entrel açam e que ainda constituem desafios do campo educativo.

Ao escovar a história a contrapelo, tecemos um movimento passado-presente-futuro, trazendo faíscas na literatura da década de 60, que se traduzem em questões ainda presentes e que nos ajudam a olhar o futuro. Qual a imagem que hoje tecemos sobre o professor esua formação? Quais as rel ações desta imagem com os antecedentes históricos que impregnam nosso olhar sobre o ofício docente? Como reconstruir nossa imagem docente no espel ho?

\section{Referências bibliográficas}

ALVES, Nilda; VILLARDI, Raquel (Org.). Multiplas leituras da nova LDB: Lei deDiretrizes e Bases da Educação Nacional (Lei 9.394/96). Rio de Janeiro: Dunya Editora, 1997.

BENJAMIN, Walter. Obras escolhidas: MagiaeTécnica, Artee Política. São Paulo: Brasiliense, 1993.

GAGNEBIN, JeanneMarie. Histórias e narração em Walter Benjamin. São Paulo: Perspectiva, 1994.

. Walter Benjamin. São Paulo: Brasiliense, 1993.

GINZBURG, Carlo. Sinais: raízes de um paradigma indiciário. In: MITOS, emblemas e sinais. São Paulo: Companhia das Letras, 1989.

KENSKI, Vani Moreira. Memória eensino. Cadernos de Pesquisa, São Paulo, n. 90, p. 4551, ago. 1994.

LE GOFF, Jacques. História e memória. Campinas: Unicamp, 1994.

LINHARES, Célia Frazão Soares. A escola e seus profissionais: tradições e contradições. Rio de Janeiro: Agir, 1989. p. 15-43 e 65-84.

Sujeito histórico e memória cultural: contradições e desafios. Rio de Janeiro: UFF, 1995. 13 p. Mimeografado.

LINHARES, Célia Frazão Soares et al. Mestrado em educação eescola básica: um encontro necessário. Educação e Realidade, Rio Grande do Sul, v. 16, n. 2, p. 59-68, jul./dez. 1991.

NÓVOA, Antonio (Org.). Diz-me como ensinas, dir-teei quem és evice-versa. In: FAZENDA, Ivani (Org.). A pesquisa em edu cação e as transformações do conhecimento. São Paulo: Papirus, 1995a. p. 29-41. 
. Sobre o conceito de memória. In: FAZENDA, Ivani (Org.). A pesquisa em educação e as transformações do conhecimento. São Paulo: Papirus, 1995b.

. Vidas de professores. Portugal: Porto Editora, 1992a.

. Os professores e sua formação. Lisboa: Publicações Dom Quixote, 1992b.

. Profissão professor. Portugal: Porto Editora, 1995c.

PESSANHA, Eurize Cal das. Ascensão e queda do professor. São Paulo: Cortez, 1994.

POPKEWITZ. A profissional ização deprofessores: al gumas notas sobresua história, ideologia e potencial. In: NÓVOA, Antonio. Os professores e sua formação. Lisboa: Publicações Dom Quixote, 1992.

SILVA, Jeferson I. da. Formação do educador e educação política. São Paulo: Cortez e Autores Associados, 1992.

SILVA, Tomaz Tadeu. Produção, conhecimento eeducação: a conexão quefal ta. Educação e Sociedade, v. 31, p. 79, dez. 1988.

SILVA, W. C. A criação dos institutos superiores de educação no Brasil: alternativa superior para a formação de professores. Caxambu, MG, 1999. Texto apresentado na 22a Reunião da Anped.

SOUZA, Inês F. de. 1994. Universidade e escola básica: construindo a unidade dialética entre intelectualidadee a prática pedagógica. Niterói: UFF, 1994. Monografia.

SOUZA, Inês Ferreira. 1997. A produção do saber docente na escola: possibilidades emanci patórias da narração na formação permanente do educador. Niterói, 1997. Dissertação (Mestrado) - UniversidadeFederal Fluminense.

\section{Bibliografia consultada na Revista Brasileira de Estudos Pedagógicos}

CENTRO BRASILEIRO DE PESQUISAS EDUCACIONAIS. Formação do professor primário no Brasil. RBEP, v. 52, n. 115, p. 113-136, jul./set. 1969.

LOURENÇO FILHO, M. B. Aperfeiçoamento do magistério. RBEP, v. 33, n. 78, p. 39-56, abr./jun. 1960.

PINHEIRO, Lucia Marques. A perfeiçoamento dos professores primários. RBEP, v. 40, n. 92, p. 52-62, out./dez. 1963.

. Treinamento, formação e aperfeiçoamento de professores primários e o Plano Nacional de Educação. RBEP, v. 46, n. 103, p. 10-64, jul./set. 1966.

REA LIZAÇÕES da Divisão deA perfeiçoamento do magistério do C.B.P.E. em 1961. RBEP, v. 37, n. 86, p. 129-138, abr.jun. 1962.

ROSAS, Paulo. Exame psicológico decandidatas ao magistério primário de Maceió. RBEP, v. 48, n. 107, p. 111-155, jul./set. 1967.

TEIXEIRA, Anísio. Mestres de amanhã. RBEP, v. 40, n. 92, p. 10-19, out./dez. 1963. 1966.

O problema de formação do magistério. RBEP, v. 46, n. 104, p. 278-287, out./dez. 
Inês Ferreira de Souza Bragança, mestre em Educação pela Universidade Federal Fluminense (UFF), éprofessora do Departamento de Educação da Faculdade deFormação de Professores da Universidade do Estado do Rio de Janeiro (FFP/Uerj) eda Universidade Estácio de Sá (Unesa).

isouza@nitnet.com.br; inesfsb@estacio.br

\section{Abstract}

This article searches for conceptions on teaching and education in articles published by Inep magazine in the 60s decade. This movement had as perspective to apprehend some flashes from the past, flashes of dangerous moments, dense with contradictions and possibilities for Brazilian Education. In order to that, we deeply focused into the study of articles that are related to those issues, so that, in a next step, being able to analyze the relations of the problem as it was placed at that context and how they are presented in today challenges.

Keywords: memory; teaching.

Recebido em 12 de julho de 2002.

A provado em 24 de junho de 2003. 